\title{
The effects of aerosols on water cloud microphysics and macrophysics based on satellite-retrieved data over East Asia and the North Pacific
}

\author{
T. Michibata ${ }^{1,3}$, K. Kawamoto ${ }^{2}$, and T. Takemura ${ }^{3}$ \\ ${ }^{1}$ Department of Earth System Science and Technology, Kyushu University, Fukuoka, Japan \\ ${ }^{2}$ Graduate School of Fisheries Science and Environmental Studies, Nagasaki University, \\ Nagasaki, Japan \\ ${ }^{3}$ Research Institute for Applied Mechanics, Kyushu University, Fukuoka, Japan \\ Correspondence to: T. Michibata (michibata@riam.kyushu-u.ac.jp)
}

Received: 16 March 2014 - Published in Atmos. Chem. Phys. Discuss.: 28 April 2014

Revised: 19 September 2014 - Accepted: 30 September 2014 - Published: 13 November 2014

\begin{abstract}
This study examines the characteristics of the microphysics and macrophysics of water clouds from East Asia to the North Pacific, using data from active CloudSat radar measurements and passive MODerate-resolution Imaging Spectroradiometer (MODIS) retrievals. Our goals are to clarify differences in microphysics and macrophysics between land and oceanic clouds, seasonal differences unique to the midlatitudes, characteristics of the drizzling process, and cloud vertical structure. In pristine oceanic areas, fractional occurrences of cloud optical thickness (COT) and cloud droplet effective radius (CDR) increase systematically with an increase in drizzle intensity, but these characteristics of the COT and CDR transition are less evident in polluted land areas. In addition, regional and seasonal differences are identified in terms of drizzle intensity as a function of the liquid water path (LWP) and cloud droplet number concentration $\left(N_{\mathrm{c}}\right)$. The correlations between drizzle intensity and LWP, and between drizzle intensity and $N_{\mathrm{c}}$, are both more robust over oceanic areas than over land areas. We also demonstrate regional and seasonal characteristics of the cloud vertical structure. Our results suggest that aerosol-cloud interaction mainly occurs around the cloud base in polluted land areas during the winter season. In addition, a difference between polluted and pristine areas in the efficiency of cloud droplet growth is confirmed. These results suggest that water clouds over the midlatitudes exhibit a different drizzle system to those over the tropics.
\end{abstract}

\section{Introduction}

The Earth's radiation budget is affected to some extent by the scattering and absorption properties of aerosol, which are referred to as aerosol-radiation interactions. In addition, aerosol particles play an important role in the climate system by serving as cloud condensation nuclei (aerosol-cloud interaction). This affects cloud optical thickness (COT) and cloud particle size (e.g., Twomey, 1977) as well as cloud lifetime (e.g., Albrecht, 1989). However, accurate and quantitative evaluation of these indirect aerosol effects is required to address the considerable uncertainty related to the heterogeneous nature of the spatial and temporal distributions of aerosols. With respect to numerical models, many climate models have been developed and improved for an accurate estimation of the global radiation balance. Practically all of the climate models, however, have uncertainty in their cloud precipitation parameterization schemes (e.g., Suzuki et al., 2013a) due to the difficulty of representing the complex aerosol-cloud interactions.

The cloud profiling radar (CPR) of CloudSat, whose mission began in 2006, may help clarify the details of cloud physical properties (Stephens et al., 2002), including vertical information that cannot be obtained from conventional satellite passive sensors, and is important in clarifying indirect aerosol effects. Research on the physical properties of water clouds has advanced significantly in the last few years. Haynes and Stephens (2007) studied the relationships between cloud thickness and precipitation in the marine tropics 
and found regional differences in the cloud vertical structure (shallow, middle, and deep modes) of precipitating clouds. Lebsock et al. (2008) investigated mainly aerosol-cloud interactions based on multi-sensor satellite observations and found a relationship between variations in the cloud liquid water path (LWP) and the thermodynamic conditions. Kubar et al. (2009) compared the physical properties of water clouds in regions over tropical and subtropical oceans and stressed the importance of cloud macrophysics and microphysics for drizzle frequency and intensity. They also investigated which parameters were important for drizzle processes, focusing on macrophysics (cloud thickness and LWP) and microphysics (cloud droplet effective radius (CDR) and cloud droplet number concentration $\left(N_{\mathrm{c}}\right)$ ).

Sorooshian et al. (2009) performed a binning study of LWP to clarify the effects of aerosol perturbation (e.g., precipitation susceptibility, aerosol cloud interactions) and suggested that intermediate LWP $\left(\sim 500-1000 \mathrm{~g} \mathrm{~m}^{-2}\right)$ cloud tends to be more susceptible to aerosol than shallow cloud with low LWP. Furthermore, they expanded the study of Stephens and Haynes (2007), who introduced a method of estimating conversion (from cloud water to rainwater) rates from CloudSat-CPR and MODerate-resolution Imaging Spectroradiometer (MODIS)-retrieved data and discussed the relationships between conversion rate and aerosol types, associated with the category of lower-tropospheric static stability (LTSS) and LWP (Sorooshian et al., 2013).

Nakajima et al. (2010) and Suzuki et al. (2010) attempted to visualize the vertical structure of cloud on a global scale using a method that they termed "contoured frequency by optical-depth diagram" (CFODD). Kawamoto and Suzuki (2012) applied CFODD to investigate precipitation processes and demonstrated that precipitation over the Amazon occurs in optically thicker locations than is the case over China.

Many researchers have investigated the physical structures and precipitation characteristics of low-level water clouds based on satellite data, as mentioned above. However, most of these studies were limited to the tropics/subtropics or areas over oceans; only a few have compared clouds over land and ocean. Very few have focused on East Asia, where some areas have significant levels of air pollution (e.g., Kawamoto and Suzuki, 2013). Therefore, clouds in these regions may exhibit drizzle characteristics that differ from those of clouds over tropical oceanic areas.

This study focuses on seasonal differences in water clouds that are characteristic of the midlatitudes and compares the characteristics of clouds over China (a region with considerable anthropogenic aerosols) with those over the North Pacific (a clean/pristine environment). We also analyze the transition processes of drizzle over both land and ocean (e.g., Nakajima et al., 2010) in the midlatitudes, which have been evaluated in only a few other studies.

\section{Data and methodology}

\subsection{CloudSat and MODIS}

CloudSat, launched by the National Aeronautics and Space Administration (NASA) in 2006, was the first project to include a spaceborne millimeter-wavelength $(3 \mathrm{~mm}$, frequency $=95 \mathrm{GHz}$ ) radar (Stephens et al., 2008) to help resolve the vertical structure of cloud droplets. The vertical and spatial resolutions of the CloudSat data products are approximately $480 \mathrm{~m}$ and $1.4 \times 1.8 \mathrm{~km}$ (across and along tracks), respectively. However, the data are twice vertically oversampled, and therefore $\sim 240 \mathrm{~m}$ sampled data are available (Stephens et al., 2008). We obtained information about cloud properties, including the visible COT and CDR near the cloud top from the 2B-TAU product (Polonsky, 2008), as well as also radar reflectivity and the cloud mask from the 2B-GEOPROF product (e.g., Mace et al., 2007; Marchand et al., 2008). We used temperature and pressure data for each altitude from the European Center for MediumRange Weather Forecasts Auxiliary (ECMWF-AUX) objective analysis (Partain, 2007). The analysis periods were June, July, and August (JJA) from 2007 to 2009 and December, January, and February (DJF) from 2006 to 2009 (i.e., December 2006-February 2009).

The passive sensor MODIS traverses aerosol-cloud properties at high frequency and resolution, using 36-channel spectral bands (Platnick et al., 2003; Remer et al., 2005). The level 3 (collection 5.1) $1^{\circ} \times 1^{\circ}$ gridded aerosol optical depth (AOD) at $0.55 \mu \mathrm{m}$ from Aqua/MODIS (Parkinson, 2003), which is a part of the A-Train constellation (Stephens et al., 2002), is used in our study.

We used the following Eq. (1) to estimate $N_{\mathrm{c}}$ (e.g., Brenguier et al., 2000; Wood, 2006; Kubar et al., 2009):

$N_{\mathrm{c}}=\sqrt{2} B^{3} \Gamma_{\mathrm{eff}}^{1 / 2} \frac{\mathrm{LWP}^{1 / 2}}{r_{e}^{3}}$,

where $B=\left(3 \pi \rho_{\mathrm{w}} / 4\right)^{1 / 3}=0.0620, \rho_{\mathrm{w}}$ is the density of liquid water, and $\Gamma_{\text {eff }}$ is the adiabatic rate of increase in the liquid water content with height, which is a function of two variables - profile of temperature and pressure - as shown in Fig. 1 of Wood (2006). The difference in CDR retrieval error between land and ocean, e.g., due to the differences in cloud type (e.g., Zhang et al., 2012), may also cause uncertainty in the estimation of $N_{\mathrm{c}}$. However, we apply a CDR uncertainty threshold of $<1 \mu \mathrm{m}$, as mentioned above, which reduces $N_{\mathrm{c}}$ uncertainty as much as possible. Other possible errors due to the assumption made in deriving $N_{\mathrm{c}}$ (e.g., adiabaticity, vertical homogeneity) are documented elsewhere (e.g., Grandey and Stier, 2010; Kubar et al., 2009). In addition, we calculated LWP by the following Eq. (2) (Brenguier et al., 2000):

$\mathrm{LWP}=5 \tau_{\mathrm{c}} r_{\mathrm{e}} / 9$, 


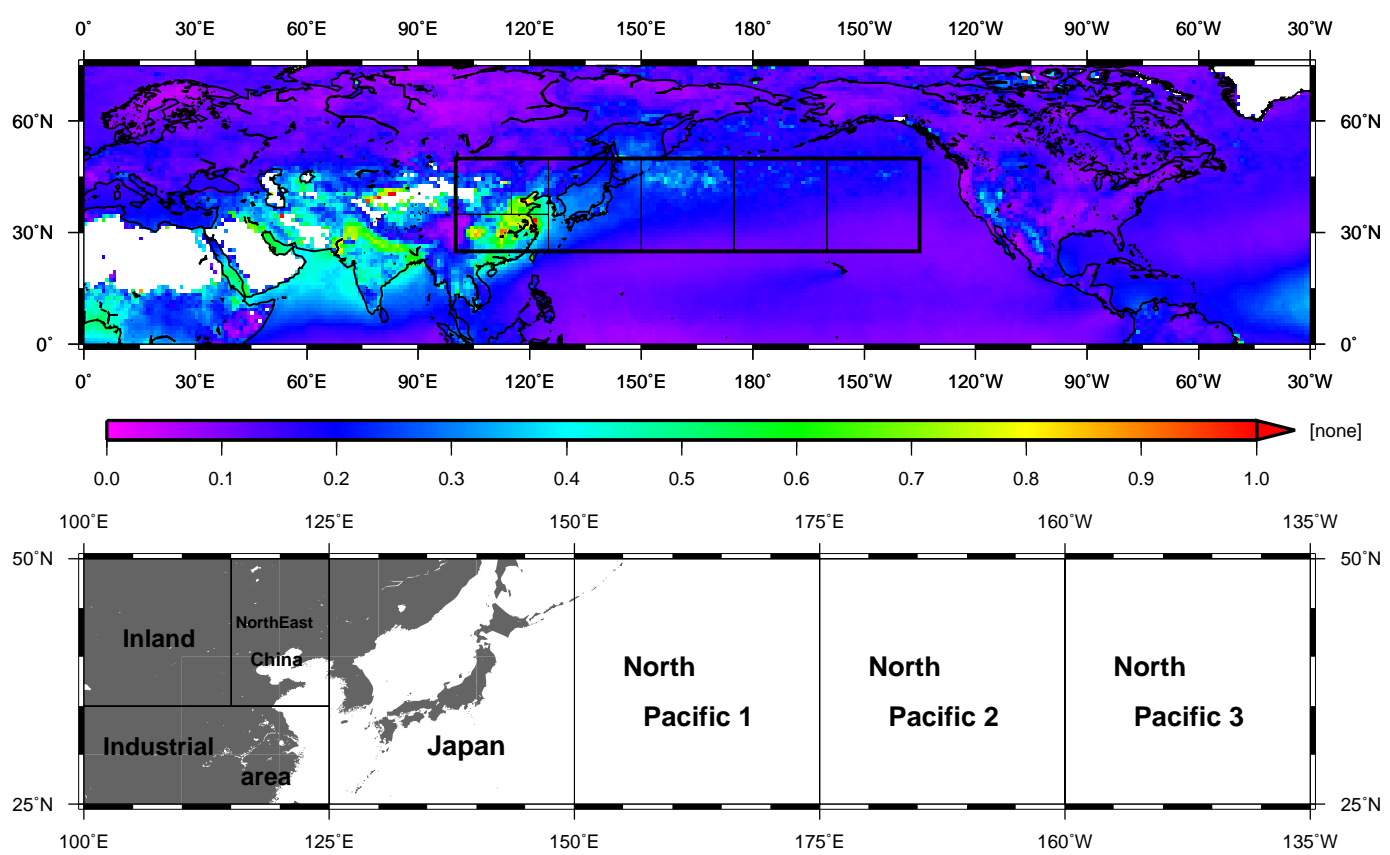

Figure 1. Whole (top) and individual (bottom) regions in this study. Spatial distribution of aerosol optical thickness $\tau_{\mathrm{a}}(550 \mathrm{~nm})$ for the 3 -year mean derived from monthly Aqua/MODIS level 3 products is illustrated in the top panel. Areas with missing values are shown in white.

where $\tau_{\mathrm{c}}$ and $r_{\mathrm{e}}$ were obtained from MODIS retrieval, matched along the CloudSat footprint (i.e., CloudSat 2BTAU product, mentioned earlier).

\subsection{Regions and methods}

Figure 1 shows maps of the regions investigated in this study. Inland includes the Gobi Desert. We selected an area of northeastern China (NE China) to study the effects of soil dust aerosols transported from the Gobi and Taklamakan deserts. Human activity generates many anthropogenic aerosols in the Industrial area, and this region is one of the most air-polluted areas in the world (upper panel of Fig. 1). Some areas of the Japan region also discharge anthropogenic aerosols, but the main reason for selecting this region is to compare it with the Industrial area. We refer to the outflow regions of anthropogenic aerosols as North Pacific 1,2, and 3 in order of their distance from East Asia. We investigated how large amounts of aerosols transported from East Asia affect cloud properties in these areas.

This study focuses only on low-level water clouds because most aerosols remain in the lower troposphere. We define water clouds as those with a cloud mask value greater than 30 (good/strong echo), which means high-confidence detection (estimated false detection $<4.3 \%$; see Marchand et al. (2008), Table 1), and a temperature above $273 \mathrm{~K}$ for the entire cloud layer. Furthermore, we use only the data with uncertainty values of less than 3 and $1 \mu \mathrm{m}$ for COT and CDR, respectively. Multilayered clouds are excluded from the analyses to avoid ambiguous statistics.

LTSS is defined as the difference in potential temperatures between $700 \mathrm{hPa}$ and the surface (Klein and Hartmann, 1993). This index was calculated from the ECMWF-AUX product (vertical temperature and pressure profiles).

\section{Results}

\subsection{Cloud physical properties for each area}

Table lists the physical properties of clouds over each of the seven areas. DJF values are given in parentheses. The land-sea mask is not applied in our analysis, and therefore the data for the Japan, NE China, and Industrial area, including the ocean part, do not necessarily represent data only over the continent. The results suggest that the precipitation occurrence is related to LWP (e.g., North Pacific 1, where higher LWP is accompanied by high '\% with rain'; Table 1), except in the Industrial area (i.e., high LWP but lower '\% with rain', and vice versa). It is noteworthy that there are large seasonal differences of more than $7 \mathrm{~K}$ in LTSS in the Industrial area. Therefore, there is a possibility of different cloud types over the Industrial area; i.e., cumulus cloud in JJA (unstable lower LTSS environment) than over the oceanic area. The passive MODIS sensor tends to retrieve errors on inhomogeneous cumulus cloud (e.g., Zhang et al., 2012; Zhang and Platnick, 2011; Zinner et al., 2010) because of its simplifying assumptions, i.e., clouds are plane-parallel 
(a)

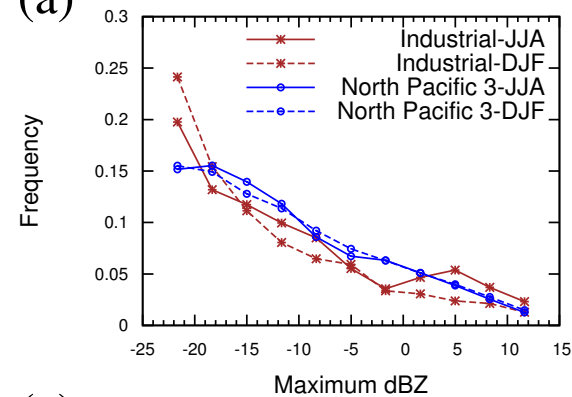

(c)

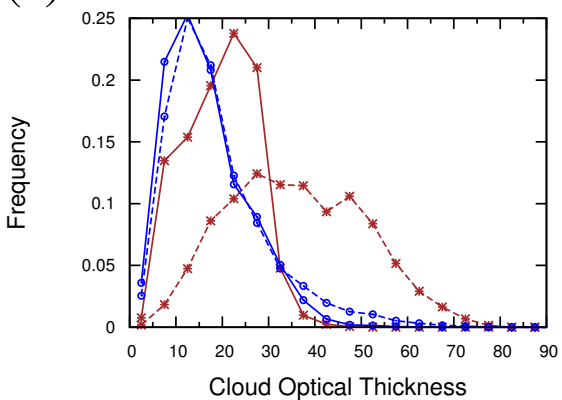

(b)

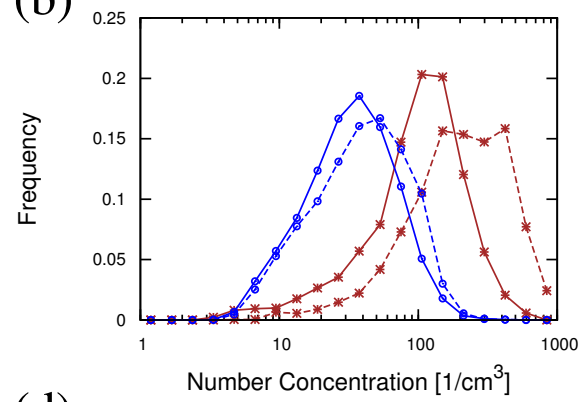

(d)

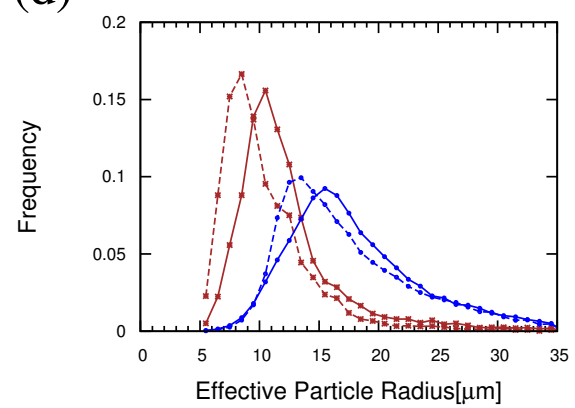

Figure 2. Probability distribution functions (PDFs) of each cloud physical variable: (a) maximum radar reflectivity $Z_{\max }$ [dBZ $\mathrm{d}_{\mathrm{e}}$, (b) cloud droplet number concentration $N_{\mathrm{c}}\left[\mathrm{cm}^{-3}\right]$, (c) cloud optical thickness $\tau_{\mathrm{c}}$, and (d) cloud effective particle radius $r_{\mathrm{e}}[\mu \mathrm{m}]$ for the Industrial area and North Pacific 3 in JJA (solid line) and DJF (dotted line).

Table 1. Cloud physical parameters in each area. JJA and DJF values are 3-year means. DJF values are shown in parentheses. Maximum values are shown in bold, and minimum values are italic. Maximum radar reflectivity in the cloud layer $\left(Z_{\max }\right)$ is used for precipitation categories (no precipitation: $Z_{\max }<-15$; drizzle: $-15 \leq Z_{\max }<0$; rain: $0 \leq Z_{\max }$ ). The Inland and NE China regions in DJF, where no or few samples met the criteria, are indicated by "not available (N/A)".

\begin{tabular}{|c|c|c|c|c|c|c|c|}
\hline & \multicolumn{4}{|c|}{ Land } & \multicolumn{3}{|c|}{ Ocean } \\
\hline & Inland & $\begin{array}{r}\mathrm{NE} \\
\text { China }\end{array}$ & $\begin{array}{r}\text { Industrial } \\
\text { area }\end{array}$ & Japan & $\begin{array}{r}\text { North } \\
\text { Pacific } 1\end{array}$ & $\begin{array}{r}\text { North } \\
\text { Pacific } 2\end{array}$ & $\begin{array}{r}\text { North } \\
\text { Pacific } 3\end{array}$ \\
\hline Number of samples & $693(0)$ & $1315(1)$ & $3927(4540)$ & 11914 (10118) & $20674(15920)$ & $25029(17455)$ & 44064 (31949) \\
\hline$\tau_{\mathrm{a}}$ & $0.29(0.18)$ & $0.40(0.30)$ & $0.49(0.44)$ & $0.23(0.21)$ & $0.24(0.16)$ & $0.17(0.14)$ & $0.14(0.14)$ \\
\hline$\tau_{\mathrm{c}}$ & 22.2 (N/A) & $24.5(0.73)$ & $19.5(35.9)$ & $22.0(26.3)$ & $19.9(21.5)$ & $17.9(19.4)$ & $16.4(18.7)$ \\
\hline$r_{\mathrm{e}}(\mu \mathrm{m})$ & 11.9 (N/A) & $11.9(10.0)$ & $12.3(10.5)$ & $15.8(14.5)$ & $18.1(17.8)$ & $18.5(18.0)$ & $18.0(17.3)$ \\
\hline $\operatorname{LWP}\left(\mathrm{g} \mathrm{m}^{-2}\right)$ & 148 (N/A) & $161(4)$ & $129(205)$ & 189 (207) & $197(215)$ & 185 (197) & $167(180)$ \\
\hline$N_{\mathrm{c}}\left(\mathrm{cm}^{-3}\right)$ & 154 (N/A) & $139(28)$ & 125 (257) & 77 (113) & $51(55)$ & $42(48)$ & $41(50)$ \\
\hline Maximum $Z_{e}\left(\mathrm{dBZ} Z_{\mathrm{e}}\right)$ & $-5.8(\mathrm{~N} / \mathrm{A})$ & $-8.1(-27.3)$ & $\mathbf{0 . 8}(-1.1)$ & $0.5(0.9)$ & $0.1(\mathbf{2 . 0})$ & $-0.3(0.7)$ & $-1.5(-1.2)$ \\
\hline$\%$ with no precipitation & 67.1 (N/A) & 70.5 (N/A) & $49.6(\mathbf{6 1 . 5})$ & $46.2(43.5)$ & $42.3(35.3)$ & $43.3(40.1)$ & $46.4(45.5)$ \\
\hline$\%$ with drizzle & 28.1 (N/A) & 26.5 (N/A) & $33.5(29.1)$ & $34.0(34.7)$ & $39.2(38.5)$ & $40.6(38.5)$ & 40.5 (40.9) \\
\hline$\%$ with rain & 4.8 (N/A) & 3.0 (N/A) & $16.9(9.4)$ & $19.8(21.8)$ & $18.5(\mathbf{2 6 . 2})$ & $16.1(21.4)$ & $13.1(13.6)$ \\
\hline Cloud-top height (km) & $3.7(\mathrm{~N} / \mathrm{A})$ & $2.7(1.4)$ & $3.4(2.3)$ & $2.4(\mathbf{2 . 4})$ & $2.1(2.2)$ & $1.9(2.0)$ & $1.8(1.7)$ \\
\hline Cloud base height $(\mathrm{km})$ & 2.7 (N/A) & $1.6(1.2)$ & $2.3(\mathbf{1 . 4})$ & $1.2(1.1)$ & $1.0(1.0)$ & $1.0(1.0)$ & $1.0(1.0)$ \\
\hline Geometrical thickness $(\mathrm{km})$ & 1.0 (N/A) & $1.1(0.2)$ & $1.2(0.9)$ & $1.2(1.3)$ & $1.1(\mathbf{1 . 3})$ & $1.0(1.0)$ & $0.8(0.8)$ \\
\hline $\operatorname{LTSS}(\mathrm{K})$ & 13.8 (N/A) & $15.2(16.8)$ & $12.2(\mathbf{1 9 . 6})$ & $16.5(15.9)$ & $\mathbf{1 9 . 4}(15.8)$ & $18.3(16.8)$ & $18.2(17.5)$ \\
\hline
\end{tabular}

and homogeneous, any effects of drizzle/rain drops are ignored (Zinner et al., 2010), etc. These assumptions may lead to a retrieval bias in CDR, e.g., shadowing effects can lead to underestimation of COT and overestimation of CDR (Marshak et al., 2006). The smaller COT and larger CDR are estimated with increasing cloud inhomogeneity, which results in an underestimation of LWP for cloudy scenes (Painemal et al., 2013). Therefore, care should be taken with regard to this background of CDR retrieval error and underestimation of LWP, especially over the Industrial area in JJA.

Figure 2 shows the probability distribution function (PDF) of each cloud physical variable. The distribution of maximum radar reflectivity in the cloud layer $\left(Z_{\max }\right)$ (Fig. 2a) is similar for both the Industrial area and North Pacific 3, 


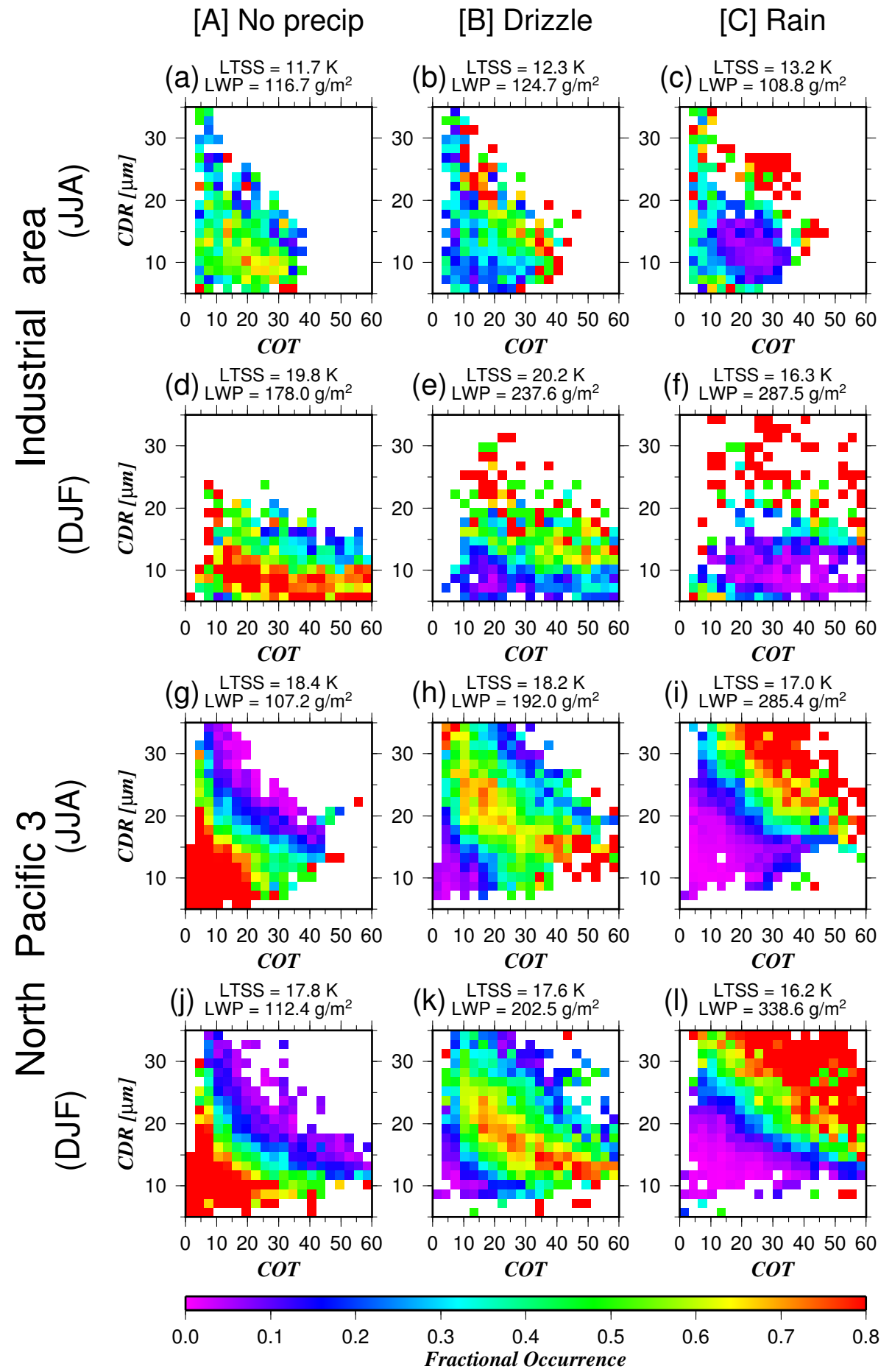

Figure 3. Fractional occurrences of cloud optical thickness (COT) and cloud droplet effective radius (CDR) for each rain category: [A] no precipitation $\left(Z_{\max }<-15\right)$, [B] drizzle $\left(-15 \leq Z_{\max }<0\right)$, and $[\mathrm{C}]$ rain $\left(0 \leq Z_{\max }\right)$. (a-c) are for the Industrial area in JJA, (d-f) for the Industrial area in DJF, (g-i) for the North Pacific 3 area in JJA, and (j-l) for the North Pacific 3 area in DJF. Averaged LWP and LTSS are shown in each diagram.

although we observed a slight shift to weaker $Z_{\max }$ for the Industrial area. We confirmed the tendency that lower CDR values, higher $N_{\mathrm{c}}$ values, and optically thicker clouds were observed over land areas than over the oceanic regions in Fig. 2 and Table, supporting the findings of previous studies (e.g., Kawamoto et al., 2001). However, these results are not 
as obvious in the region over Japan as in other land areas Inland, NE China, or the Industrial area. It is possible that the properties of clouds over NE China are affected in a complex manner by dust aerosols from the adjacent western deserts and emissions of anthropogenic aerosols from highly populated areas, such as Beijing. The North Pacific 1 area has slightly higher values for COT, LWP, and $N_{\mathrm{c}}$ compared with the other oceanic areas, and the values of CDR are almost the same for all oceanic areas. Small seasonal differences are observed during JJA and DJF over the three oceanic areas; these differences are more obvious over the four land areas, which may be due to the high levels of aerosols in DJF, when atmospheric conditions are most stable.

The mode radii are approximately $15 \mu \mathrm{m}$ over the three oceanic areas, whereas they are approximately $9 \mu \mathrm{m}$ over the Industrial area in DJF, which may result in less efficient precipitation. The following subsections discuss how differences in the physical properties of clouds over land and ocean regions affect rainfall characteristics.

\subsection{COT-CDR diagram}

COT and CDR are commonly considered cloud physical variables. The fact that the correlation between these parameters reflects cloud growth (only liquid phase warm cloud) and precipitation processes has been well documented in previous studies based on satellite observations (e.g., Nakajima et al., 1991; Nakajima and Nakajima, 1995). That is, both COT and CDR increase early in the growth process of cloud droplets, resulting in a positive correlation between them. The cloud particles grow to almost $15 \mu \mathrm{m}$, and precipitation begins. With precipitation, COT decreases and CDR increases due to coalescence. This precipitation process leads to a negative correlation pattern. Suzuki et al. (2006) extended these analyses and successfully simulated the pattern using a spectral-bin microphysics model. Suzuki et al. (2011) documented fractional occurrences as a function of COT and CDR for each rain category (no precipitation, drizzle, and rain) and compared A-Train observations with model simulations.

Figure 3 shows fractional occurrences on COT-CDR diagrams for each rain category ([A] no precipitation: $Z_{\max }<$ -15 ; [B] drizzle: $-15 \leq Z_{\max }<0$; and [C] rain: $0 \leq Z_{\max }$ ) (Comstock et al., 2004; Stephens and Haynes, 2007). The diagrams in the pristine remote ocean (North Pacific 3, Fig. $3 g-1)$ reveal that the main group systematically shifts from the lower COT-CDR region to the higher COT-CDR region with an increase in the rain category (i.e., from no precipitation to rain, with a monotonous increase in LWP and a slight decrease in LTSS) during both seasons. This tendency was also reported by Suzuki et al. (2011) and Kawamoto and Suzuki (2013). The fact that JJA (Fig. 3g-i) and DJF (Fig. 3j-1) have similar distributions suggests that the relation between COT and CDR has considerable universality with regard to the rain categories over oceanic areas. However, (a)

Inland

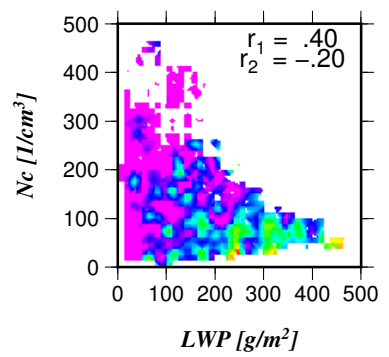

(b)

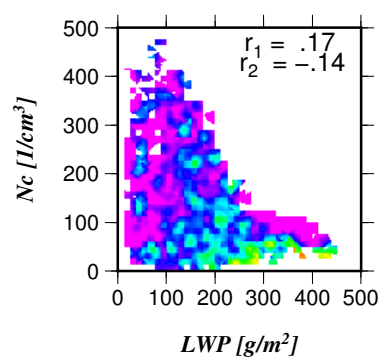

(c) Industrial area

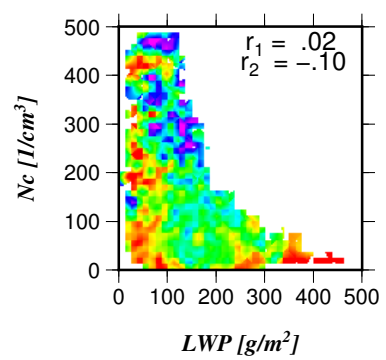

(d)

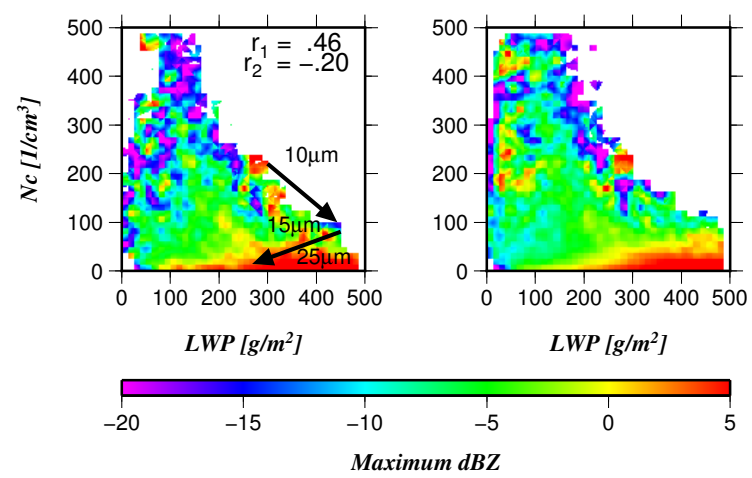

(e) North Pacific 1

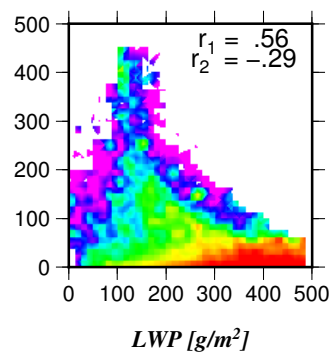

(f) North Pacific 2

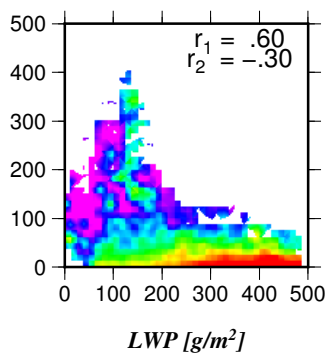

(g) North Pacific 3

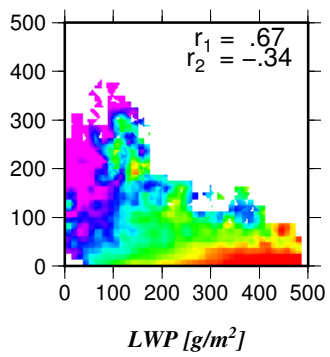

(h) All Regions
Figure 4. The distribution of maximum radar reflectivity $Z_{\max }$ as a function of LWP and $N_{\mathrm{c}}$ during JJA: (a) Inland, (b) NE China, (c) Industrial area, (d) Japan, (e) North Pacific 1, (f) North Pacific 2, (g) North Pacific 3, and (h) the mean value of all regions. $r_{1}$ is a correlation coefficient between LWP and $Z_{\max }$, and $r_{2}$ is a correlation coefficient between $N_{\mathrm{c}}$ and $Z_{\max }$. The black arrows in (d) indicate one possible interpretation of growing processes from cloud droplet to drizzle and raindrop (see text for details). 
(a)

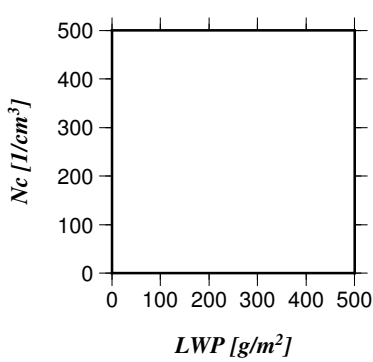

(b) NE China

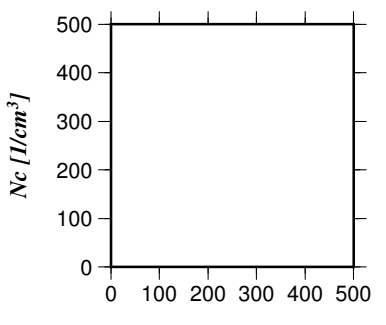

LWP $\left[g / m^{2}\right]$

(c) Industrial area

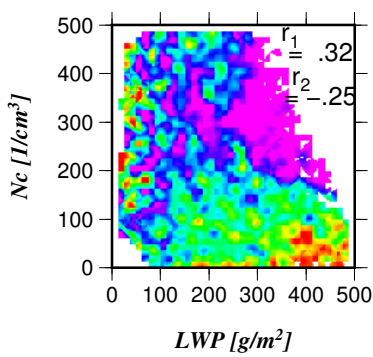

(d)

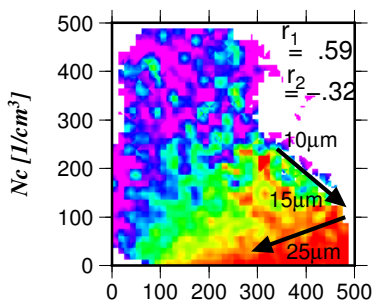

Japan

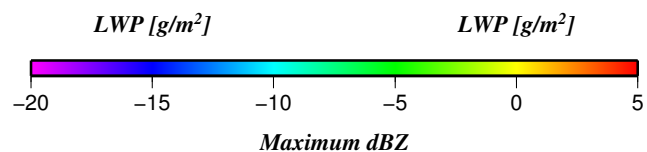

Figure 5. The distribution of maximum radar reflectivity $Z_{\max }$ as a function of LWP and $N_{\mathrm{c}}$ during DJF: (a) Inland, (b) NE China, (c) Industrial area, (d) Japan, (e) North Pacific 1, (f) North Pacific 2, (g) North Pacific 3, and (h) the mean value of all regions. $r_{1}$ is a correlation coefficient between LWP and $Z_{\max }$, and $r_{2}$ is a correlation coefficient between $N_{\mathrm{c}}$ and $Z_{\max }$. The black arrows in (d) indicate one possible interpretation of growing processes from cloud droplet to drizzle and raindrop (see text for details). The diagrams of (a) Inland and (b) NE China are not shown because no data are available. in the Industrial area where air pollution by anthropogenic aerosols is severe, the transition pattern is not as clear as over the ocean, and the variations of LWP are relatively small. The category Rain in JJA (Fig. 3c) has relatively high values of fractional occurrence (approximately $0.2-0.5$ ) in the small COT-CDR region (COT $<15, \mathrm{CDR}<15 \mu \mathrm{m})$, while most values in this region (see Fig. 3i, 1) are less than 0.2. Furthermore, we found that large numbers of samples are concentrated in this region and that the cloud-top height in the Industrial area is much higher $(3.3 \mathrm{~km})$ than that in the North Pacific 3 area $(2.4 \mathrm{~km})$. These findings suggest the existence of other predominant factors that affect drizzle intensity in the Industrial area during JJA, in addition to COT and CDR. Matsui et al. (2004) reported that not only the amount of aerosol but also the static stability was important for growth from cloud droplets into drizzle. The vertical inhomogeneity of CDR (larger particles appear in the lower part of clouds) is one possible reason for this observation. Further analyses are required to clarify this issue.

\subsection{Transition pattern of precipitation}

Some researchers have considered how the properties of clouds over land and ocean differently affect precipitation efficiency. Leon et al. (2008) analyzed CloudSat and CloudAerosol Lidar and Infrared Pathfinder Satellite Observation (CALIPSO) data and illustrated the global distribution of drizzle frequency as a function of LWP and CDR. We used $N_{\mathrm{c}}$ instead of CDR because we focused on differences in the amount of aerosol between land (polluted) and ocean (cleaner) regions. Kubar et al. (2009) also investigated the drizzle frequency of water clouds over oceanic areas in the tropics and subtropics as a function of a typical macrophysical variable (LWP) and a typical microphysical variable $\left(N_{\mathrm{c}}\right)$. They found that the drizzle frequency increased with LWP when $N_{\mathrm{c}}$ was constant and decreased with increasing $N_{\mathrm{c}}$ and constant LWP. We focused on the midlatitudes in the Northern Hemisphere, but more detailed analyses of midlatitude regions would be valuable.

Figures 4 and 5 show the $Z_{\max }$ distribution as a function of LWP and $N_{\mathrm{c}}$ because we focused on the transition process of drizzle intensity rather than its frequency. Over three ocean regions (Figs. $4 \mathrm{e}-\mathrm{g}$ and $5 \mathrm{e}-\mathrm{g}$ ), the drizzle intensity increased with increasing LWP under a constant $N_{\mathrm{c}}$ and increased with decreasing $N_{\mathrm{c}}$ under a constant LWP. It is important to clarify the physical parameters of clouds to understand the behavior of drizzle over the midlatitudes as well as over the tropics/subtropics. As the correlation coefficient $r_{1}$ between LWP and $Z_{\max }(\sim 0.6)$ is greater than $r_{2}$ between $N_{\mathrm{c}}$ and $Z_{\max }(\sim-0.3)$ in these areas, LWP has a stronger correlation than $N_{\mathrm{c}}$ with drizzle intensity. This correlation is less clear over land areas than over oceanic areas, as shown in Figs. $4 \mathrm{a}-\mathrm{d}$ and $5 \mathrm{c}-\mathrm{d}$. In particular, high values of $Z_{\max }$ over the Industrial area are scattered during JJA because parameters other than LWP and $N_{\mathrm{c}}$ have strong effects on the drizzle 
(a)

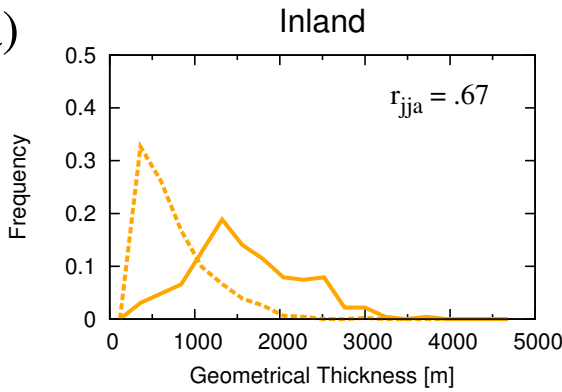

(b)

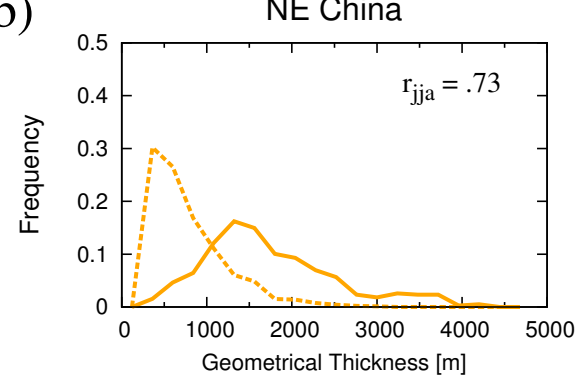

(c)

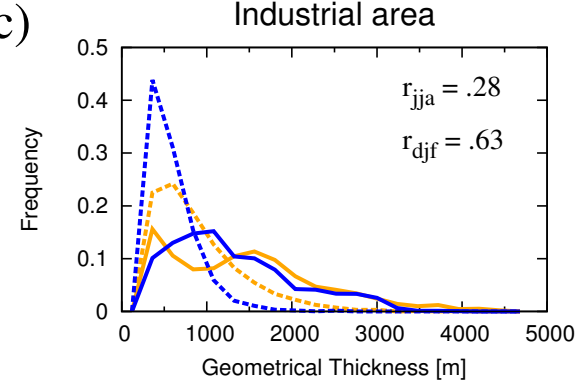

(d)

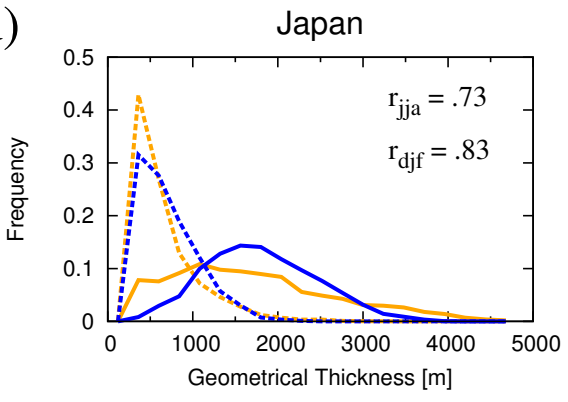

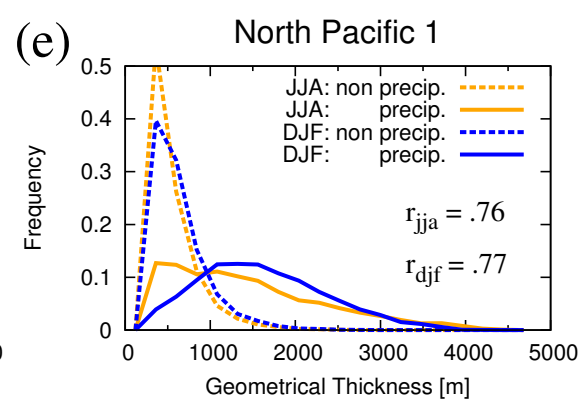

(f)
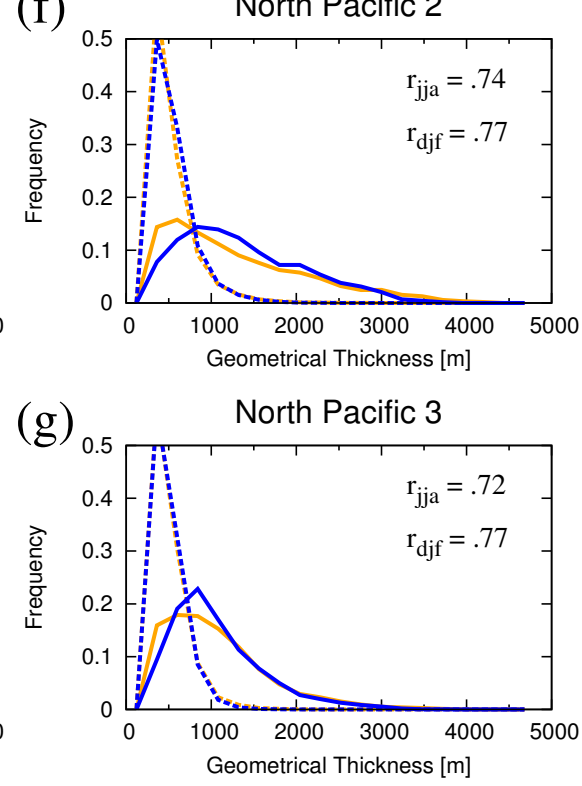

Figure 6. PDFs of cloud geometrical thickness for non-precipitating cloud (dotted line) and drizzling/precipitating cloud (solid line). $r_{\mathrm{jja}}$ is the correlation coefficient between cloud geometrical thickness and $Z_{\max }$ in JJA season, and $r_{\mathrm{djf}}$ is the same but in the DJF season. The DJF values of (a) Inland and (b) NE China are not shown because no data are available.

transition process (from cloud droplet to drizzle and precipitation). This is consistent with our hypothesis that there is a more important dominant factor than cloud physical properties, such as COT, CDR, LWP, and $N_{\mathrm{c}}$, over the Industrial area in JJA. The seasonal difference is more obvious over the land areas than over the oceanic areas, with the magnitudes of the correlation coefficients $r_{1}$ and $r_{2}$ being higher in DJF than in JJA. The land areas in JJA are in the unstable lower LTSS environment, with the exception of Japan. The low specific heat of the land surface would yield unstable conditions due to heating by stronger shortwave radiation in the JJA season. Such local heating may result in forced precipitation. This is responsible for the scattered distribution of high $Z_{\max }$ values. In addition, variations in the dynamics over land areas (e.g., vertical velocity) would also be associated with this seasonal difference.

Values of $Z_{\max }$ greater than $0 \mathrm{dBZ}_{\mathrm{e}}$ (orange and red in Fig. 4) are uncommon in the Inland and NE China areas during JJA, which indicates very few precipitating clouds. Over these regions in DJF, generally only few water clouds 


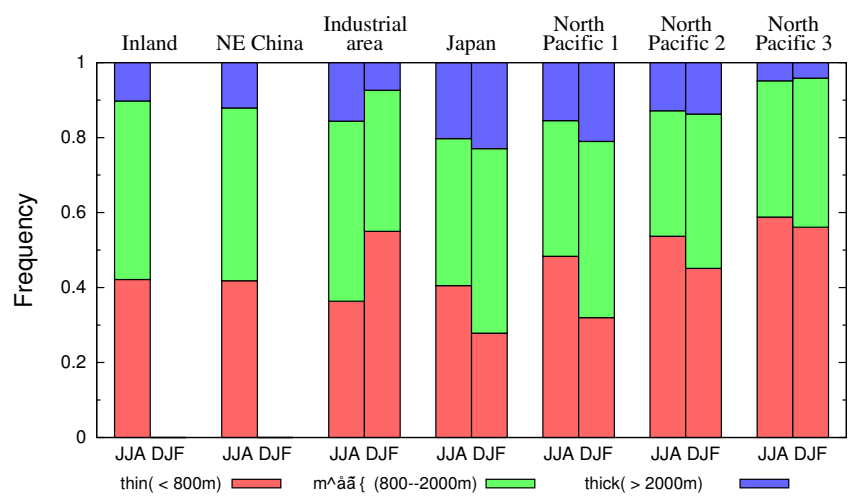

Figure 7. Histogram of cloud geometrical thickness. Thin (red), medium (green), and thick (blue) clouds are defined using threshold values of 800 and $2000 \mathrm{~m}$. The DJF values of Inland and NE China are not shown because there is no available data.

are observed, due to low temperature and/or low water vapor levels. In the Industrial area, there are some occasions when $N_{\mathrm{c}}$ is larger than $500 \mathrm{~cm}^{-3}$, and $Z_{\max }$ values are lower as $N_{\mathrm{c}}$ becomes larger during DJF. Even LWP values, which are more strongly correlated with drizzle intensity, are larger. These findings suggest that the cloud lifetime increases due to storage of water within the cloud layer. These findings are also observed in Japan (Fig. 5d), where a significant transition pattern appears as follows: LWP of $300 \mathrm{~g} \mathrm{~m}^{-2}$ and $N_{\mathrm{c}}$ of $250 \mathrm{~cm}^{-3}$, to LWP of $450 \mathrm{~g} \mathrm{~m}^{-2}$ and $N_{\mathrm{c}}$ of $100 \mathrm{~cm}^{-3}$, to LWP of $300 \mathrm{~g} \mathrm{~m}^{-2}$ and $N_{\mathrm{c}}$ of $15 \mathrm{~cm}^{-3}$, as shown by the black arrows in Figs. 4d and 5d. LWP values increase to $400-500 \mathrm{~g} \mathrm{~m}^{-2}$ as $N_{\mathrm{c}}$ values decrease because drizzle occurs only inside the cloud layer with no loss of water. At the same time, CDR values increase slowly within the range of $10-15 \mu \mathrm{m}$ and then rapidly to higher values $(15-25 \mu \mathrm{m})$, which leads to precipitation. The conditions in Japan are not as clean as in the three oceanic regions but are not as polluted as in the Industrial area, which is likely the reason for this V-shaped transition pattern.

\subsection{Cloud vertical structure}

Cloud geometrical thickness is a cloud macrophysical variable, in addition to the cloud-top height and LWP. Over the tropical ocean, cloud-top height is offset by a constant from the cloud geometric thickness, because the cloud base height is almost constant (e.g., Kubar et al., 2009). Cloud base height is, however, not always constant over midlatitudes, particularly over land. Therefore, we use cloud geometrical thickness as a representative macrophysical variable. In fact, cloud geometrical thickness has a robust correlation with $Z_{\max }(0.28-0.83$; shown in Fig. 6), which is an index of precipitation intensity, stronger than the relationship between cloud-top height and $Z_{\max }(0.04-0.63)$. However, it should be noted that the "cloud geometrical thickness" mentioned here does not always accurately represent the cloud thickness. Specifically, in some cases of non-precipitating cloud, determination of the cloud base is difficult because the reflectivity at this point is too weak to be observed. However, in the case of precipitating cloud, the detected value would include not only the cloud but also some of the precipitating layer. Thus, the "cloud geometrical thickness" represents the detected hydrometer thickness.

The PDFs of cloud geometrical thickness are shown in Fig. 6. Solid and dotted lines represent drizzling/precipitating and non-precipitating cloud, respectively. The correlations between cloud geometrical thickness and $Z_{\max }$ for JJA and DJF are denoted as $r_{\mathrm{jja}}$ and $r_{\mathrm{djf}}$, respectively. Almost all of the non-precipitating clouds have geometrical thickness less than $1000 \mathrm{~m}$, and the clouds with precipitation are $\sim 500-1000 \mathrm{~m}$ thicker. This trend and strong correlation between cloud geometrical thickness and $Z_{\max }$ suggest the importance of cloud geometrical thickness for the occurrence of precipitation. The modal cloud geometrical thickness of the nonprecipitating category is $\sim 500 \mathrm{~m}$ for all seven regions during both seasons. On the other hand, the precipitating clouds have large seasonal variability. For example, oceanic clouds (Fig. 6e-g) become thicker in DJF. Figure 7 shows a histogram of cloud geometrical thickness for thin $(<800 \mathrm{~m}$; red), medium (800-2000 m; green), and thick ( $\geq 2000 \mathrm{~m}$; blue) clouds, which correspond roughly to non-precipitating, drizzling, and precipitating clouds, respectively. The LTSS values listed in Table, which represent the air stability, tend to be consistent with the cloud geometrical thickness. More specifically, medium or thicker clouds exist predominantly in the unstable environment over the Industrial area in JJA (i.e., LTSS $=12.2 \mathrm{~K}$ ). Conversely, in the stable environment in DJF (i.e., LTSS $=19.6 \mathrm{~K}$ ), thinner clouds are predominant. Similar to this tendency, the cloud geometrical thickness, which reflects the seasonal difference in LTSS, is also seen among other regions.

Lebsock et al. (2008) confirmed that high-aerosol conditions tend to decrease LWP in non-precipitating clouds, and the magnitude of the reduction in LWP is greater under the unstable low LTSS environment. These findings suggest the importance of LWP and thermodynamics in understanding aerosol-cloud interactions (L'Ecuyer et al., 2009). We further investigated the cloud vertical structure based on a comparison with the atmospheric conditions (pristine or polluted) associated with LWP and LTSS. Use of the CFODD to illustrate cloud vertical structure facilitates the identification of associations with cloud optical properties, particularly for single-layered water clouds (e.g., Nakajima et al., 2010; Suzuki et al., 2010). In general, the vertical and horizontal axes are allocated to geometrical height and radar reflectivity, respectively, when illustrating the frequency of the vertical radar profile. CFODD visualization methods apply the in-cloud optical depth (ICOD) instead of altitude as the vertical axis. In this way, normalization of the vertical coordinate by ICOD facilitates the interpretation, focusing on optical properties using composited clouds of different geometrical 


\section{[A] $05 \leq \mathrm{CDR}<12 \mu \mathrm{m} \quad[\mathrm{B}] 12 \leq \mathrm{CDR}<18 \mu \mathrm{m} \quad[\mathrm{C}] 18 \leq \mathrm{CDR}<35 \mu \mathrm{m}$}
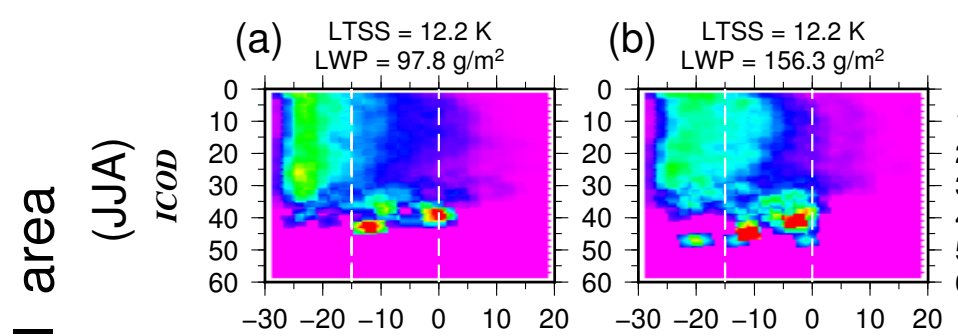

(c) $\quad$ LTSS $=12.7 \mathrm{~K}$

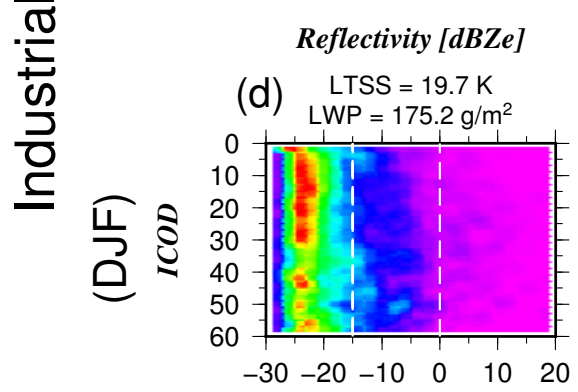

Reflectivity [dBZe]

(e) $\mathrm{LTSS}=19.6 \mathrm{~K}$
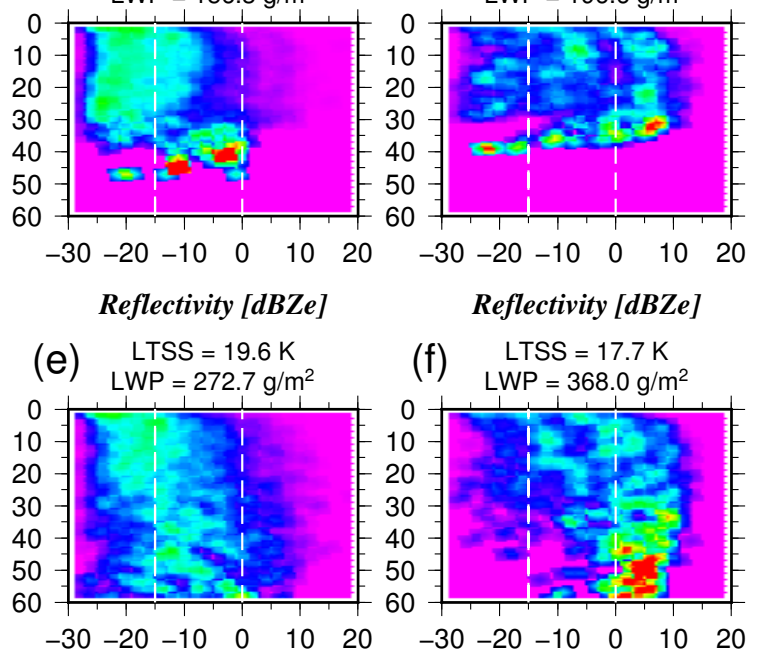

Reflectivity [dBZe]

Reflectivity [dBZe]

\section{Reflectivity [dBZe]}

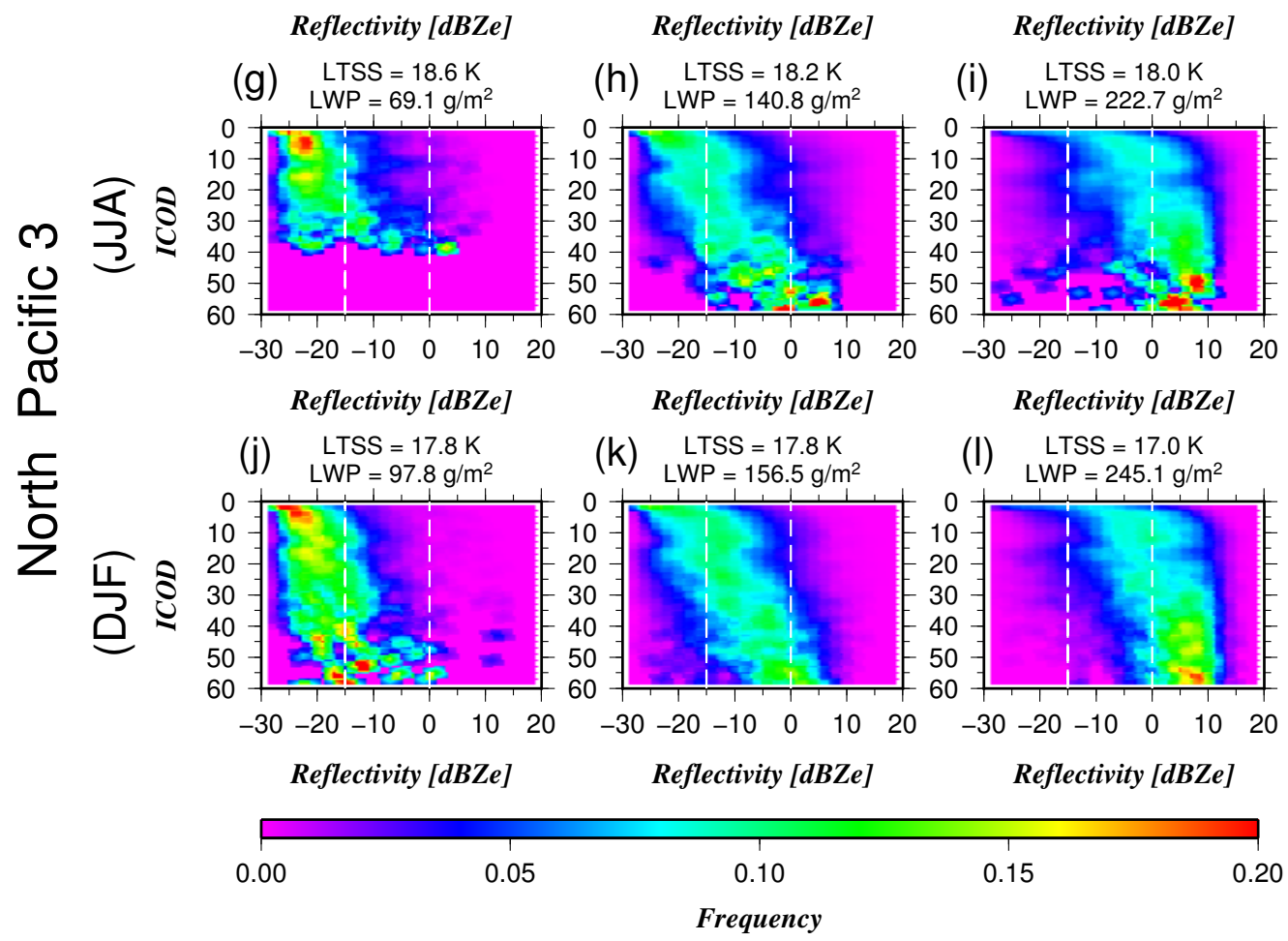

Figure 8. Contoured frequency by optical-depth diagrams (CFODDs) as a function of CDR, [A] 5-12 $\mu \mathrm{m},[\mathrm{B}] 12-18 \mu \mathrm{m},[\mathrm{C}] 18-35 \mu \mathrm{m}$. $(\mathbf{a}-\mathbf{c})$ are for the Industrial area in JJA, $(\mathbf{d}-\mathbf{f})$ for the Industrial area in DJF, $(\mathbf{g}-\mathbf{i})$ for the North Pacific 3 area in JJA, and (j-l) for the North Pacific 3 area in DJF. Two white dotted lines are drawn as threshold radar reflectivity values, $-15 \mathrm{dBZ}_{\mathrm{e}}$ and $0 \mathrm{dBZ}$, which are taken as the boundaries between cloud particles and drizzle, and between drizzle and rain, respectively. Averaged LWP and LTSS are also shown in each CFODD.

thicknesses. We obtained information on the layered optical depth from the $2 \mathrm{~B}-\mathrm{TAU}$ product.
CFODDs of each CDR bin ([A] 5-12 $\mu \mathrm{m}$, [B] 12-18 $\mu \mathrm{m}$, [C] 18-35 $\mu \mathrm{m}$ ) over the Industrial area and North Pacific 3 are presented in Fig. 8. Although LTSS is correlated with cloud geometrical thickness, as mentioned earlier, LTSS seems 
Table 2. LWP and its rate of increase for each CFODD.

\begin{tabular}{|c|c|c|c|c|c|}
\hline & [A] $05 \leq \mathrm{CDR}<12 \mu \mathrm{m}$ & & [B] $12 \leq \mathrm{CDR}<18 \mu \mathrm{m}$ & & [C] $18 \leq \mathrm{CDR}<35 \mu \mathrm{m}$ \\
\hline \multicolumn{6}{|l|}{ Industrial area } \\
\hline JJA LWP $\left(\mathrm{g} \mathrm{m}^{-2}\right)$ & 97.8 & & 156.3 & & 196.6 \\
\hline Rate of increase & & 1.60 & & 1.26 & \\
\hline DJF LWP $\left(\mathrm{g} \mathrm{m}^{-2}\right)$ & 175.2 & & 272.7 & & 368.0 \\
\hline Rate of increase & & 1.56 & & 1.35 & \\
\hline \multicolumn{6}{|l|}{ North Pacific 3} \\
\hline JJA LWP $\left(\mathrm{g} \mathrm{m}^{-2}\right)$ & 69.1 & & 140.8 & & 222.7 \\
\hline Rate of increase & & 2.04 & & 1.58 & \\
\hline DJF LWP $\left(\mathrm{g} \mathrm{m}^{-2}\right)$ & 97.8 & & 156.5 & & 245.1 \\
\hline Rate of increase & & 1.60 & & 1.57 & \\
\hline
\end{tabular}

to have little relation to the cloud growth process because the values are almost identical among the three CDR bins. The CFODDs show that the LWP increases monotonically with increasing CDR, which corresponds to the transition from cloud particle (category [A]) to drizzle (category [B]) and raindrop (category $[\mathrm{C}]$ ). That is, CDR bin $[\mathrm{A}]$ represents evaporation and condensation processes, and CDR bins [B] and [C] represent mainly collision and coalescence processes. Therefore, an increase in LWP with an increase in CDR is expected. However, the rate of increase of LWP differs significantly between the Industrial area and North $\mathrm{Pa}$ cific 3, as shown in Table 2. That is, the rate of increase over North Pacific 3 is greater than that over the Industrial area. This result implies that the clouds over North Pacific 3 are more efficient than those over the Industrial area in terms of cloud droplet growth. Over the Industrial area in DJF, which is in the stable and high-LTSS environment, nonprecipitating clouds are dominant $(61.5 \%$; see Table ) and contain much cloud water, as depicted in Fig. 8d. This may suggests the occurrence of the second indirect effect (Albrecht, 1989). Under such high-LWP and small-CDR conditions, cloud albedo can also increase, as can be seen in the following Eq. (3), which is another form of Eq. (1):

$\tau_{\mathrm{c}}=\frac{9 \mathrm{LWP}}{5 r_{\mathrm{e}}}$.

In fact, the COT in DJF ( $\left.\tau_{\mathrm{c}}=35.9\right)$ is much higher than that in JJA $\left(\tau_{\mathrm{c}}=19.5\right)$.

We can see non-precipitating clouds mainly in the smallest CDR bin (CDR $<12 \mu \mathrm{m})$, and we can also see an obvious transition of the CFODD to drizzle $(12 \mu \mathrm{m} \leq \mathrm{CDR}<18 \mu \mathrm{m})$ and rain $(18 \mu \mathrm{m} \leq \mathrm{CDR})$ phases. In addition, there is a clear difference between the CFODDs of the Industrial area and North Pacific 3, with regard to the transition process for drizzling clouds. More specifically, the CFODDs over the polluted land area transit ICOD mainly from near the cloud top to the cloud base, while those over the ocean transit mainly in the deeper ICOD region (approximately over 30). This feature is consistent with some previous reports (e.g., Naka- jima et al., 2010; Suzuki et al., 2010, 2011). We interpret this characteristic of CFODDs as a result of the suppression of precipitation due to high concentrated aerosols around the cloud base (large part of ICOD) over the Industrial area. DJF is a dry season over midlatitudes in the Northern Hemisphere, and the stable and high-LTSS environment results in a high aerosol concentration near the surface. Therefore, an aerosol-cloud interaction may occur that results in weaker radar reflectivity in the larger ICOD region. This may be a possible hypothesis, and further analysis (e.g., sensitivity experiments using numerical modeling) is required in order to enhance the credibility. It is also possible that the difference in cloud vertical structure between land and ocean is caused by the difference in updraft strength (Nakajima et al., 2010) or other meteorological factors as well. The mission Earth Clouds, Aerosols and Radiation Explorer (EarthCARE), which will start in 2016, is helpful because it will equip the CPR with Doppler speed sensor functions (e.g., Sy et al., 2013; Nakatsuka et al., 2012; Schutgens, 2008) that can detect vertical velocity. In addition, numerical modeling experiments are required for further understanding of aerosol-cloud-radiation interaction.

Lebsock et al. (2008) emphasized the importance of performing investigations on regional and seasonal scales in both numerical modeling and observational studies to gain a more detailed understanding of cloud dynamics. Suzuki et al. (2013b) also suggested that the complex behavior of CFODDs at different latitudes (see their Fig. S3) and models could not reproduce the satellite-observed CFODDs due to a lack of knowledge concerning the parameterization of cloud dynamics at different latitudes. The results of the present study, based on regional and seasonal analysis associated with aerosol-cloud interaction, will contribute to the improvement of cloud physical parameterization in numerical models.

The effects of the spatial difference of meteorology on aerosol-cloud interaction were not considered in our study; therefore, further analyses are necessary. We must consider the two following ideas carefully: one is the fact that genuine 
aerosol-cloud interactions may behave differently under different meteorological conditions; and the other is the fact that meteorology may drive aerosol-cloud relationships (even in the absence of any aerosol-cloud interactions). Such meteorological gradients sometimes cause spurious correlations (Grandey and Stier, 2010).

For example, the difference in the autoconversion rate over land and ocean, or in JJA and DJF, may provide some insight into the indirect aerosols effects (e.g., Stephens and Haynes, 2007; Sorooshian et al., 2013). Although the data presented here are insufficient to link the ocean-versus-land differences to aerosol effects, further studies to determine the effects of atmospheric conditions (i.e., aerosol concentration, static stability) on cloud physical structure would be valuable.

\section{Conclusions}

We conducted a comparative study of the physical properties of water clouds over the region from East Asia to the North Pacific in the midlatitudes based on CloudSat/CPR and Aqua/MODIS retrievals. In addition to confirming several known characteristics regarding cloud physical properties, such as larger $N_{\mathrm{c}}$, smaller CDR, and higher COT values over land, we found that the cloud differences over land versus the ocean are more obvious during DJF than JJA.

In the pristine area, we found a clear tendency for lower to higher COT-CDR with rising precipitation categories during both JJA and DJF. However, this transition pattern does not appear clearly in the polluted area during JJA, and precipitation occurs even in the lower COT-CDR region.

An investigation of the transition process of precipitation reveals that, during DJF, the polluted areas have larger $N_{\mathrm{c}}$ values, and the clouds could contain much more LWP with higher $N_{\mathrm{c}}$ values than during JJA. Oceanic cloud properties over the midlatitudes do not change significantly between the two seasons, and their behavior is similar to that of oceanic clouds over the tropics/subtropics. However, we observe considerable seasonal differences over land.

Such differences also appear in the LTSS. Although the LTSS is correlated with cloud geometrical thickness, it is less important for the cloud growth process. On the other hand, LWP increases monotonically with growing CDR. However, we confirmed a smaller rate of increase in LWP over polluted land. In addition, we found a difference in "contoured frequency by optical-depth diagram" (CFODD) between the pristine oceanic area and the polluted land area, implying aerosol-cloud interaction. However, we cannot completely exclude the possibility that other meteorological factors may be responsible for the differences between land and ocean.

To clarify these differences in cloud properties and drizzle characteristics between land and ocean, and between the tropics/subtropics and midlatitudes, it is important to estimate the radiation budget accurately. We determined some of the characteristics of aerosol-cloud interaction based only on satellite data. However, composite studies with numerical modeling (e.g., sensitivity experiments for the influence of aerosol and atmospheric stability to cloud physics) are required to gain a detailed understanding of aerosol-cloud interaction. This study does not preclude the possible effect of spatial gradient changes in the meteorology on aerosol-cloud interaction, and further analyses taking such environmental conditions into consideration are required.

Acknowledgements. The CloudSat and MODIS data products were provided by the CloudSat Data Processing Center at CIRA/Colorado State University and the MODIS Atmosphere Discipline Group, respectively. The authors would like to express their gratitude to the CloudSat and MODIS science teams. This study was partly supported by the Funding Program for Next Generation World-Leading Researchers of the Cabinet Office, Government of Japan (GR079), and the Environment Research and Technology Development Fund (S-12-3) of the Ministry of the Environment, Japan. Constructive and insightful comments from two anonymous reviewers greatly helped to improve the manuscript.

Edited by: P. Stier

\section{References}

Albrecht, B. A.: Aerosols, cloud microphysics, and fractional cloudiness, Science, 245, 1227-1230, 1989.

Brenguier, J.-L., Pawlowska, H., Lothar, S., Rene, P., Jurgen, F., and Fouquart, Y.: Radiative properties of boundary layer clouds: droplet effective radius versus number concentration, J. Atmos. Sci., 57, 803-821, 2000.

Comstock, K. K., Wood, R., Yuter, S. E., and Bretherton, C. S.: Reflectivity and rain rate in and below drizzling stratocumulus, Quart. J. Roy. Meteor. Soc., 130, 2891-2918, doi:10.1256/qj.03.187, 2004.

Grandey, B. S. and Stier, P.: A critical look at spatial scale choices in satellite-based aerosol indirect effect studies, Atmos. Chem. Phys., 10, 11459-11470, doi:10.5194/acp-10-11459-2010, 2010.

Haynes, J. M. and Stephens, G. L.: Tropical oceanic cloudiness and the incidence of precipitation: early results from CloudSat, Geophys. Res. Lett., 34, L09811, doi:10.1029/2007GL029335, 2007.

Kawamoto, K. and Suzuki, K.: Microphysical transition in water clouds over the Amazon and China derived from spaceborne radar and radiometer data, J. Geophys. Res., 117, D05212, doi:10.1029/2011JD016412, 2012.

Kawamoto, K. and Suzuki, K.: Comparison of water cloud microphysics over mid-latitude land and ocean using CloudSat and MODIS observations, J. Quant. Spectrosc. Ra., 122, 13-24, doi:10.1016/j.jqsrt.2012.12.013, 2013.

Kawamoto, K., Nakajima, T., and Nakajima, T. Y.: A global determination of cloud microphysics with AVHRR remote sensing, J. Climate, 14, 2054-2068, 2001.

Klein, S. A. and Hartmann, D. L.: The seasonal cycle of low stratiform clouds, J. Climate, 6, 1587-1606, 1993. 
Kubar, T. L., Hartmann, D. L., and Wood, R.: Understanding the importance of microphysics and macrophysics for warm rain in marine low clouds, Part I: Satellite observations, J. Atmos. Sci., 66, 2953-2972, doi:10.1175/2009JAS3071.1, 2009.

Lebsock, M. D., Stephens, G. L., and Kummerow, C.: Multisensor satellite observations of aerosol effects on warm clouds, J. Geophys. Res., 113, D15205, doi:10.1029/2008JD009876, 2008.

L'Ecuyer, T. S., Berg, W., Haynes, J., Lebsock, M., and Takemura, T.: Global observations of aerosol impacts on precipitation occurrence in warm maritime clouds, J. Geophys. Res., 114, D09211, doi:10.1029/2008JD011273, 2009.

Leon, D. C., Wang, Z., and Liu, D.: Climatology of drizzle in marine boundary layer clouds based on 1 year of data from CloudSat and Cloud-Aerosol Lidar and Infrared Pathfinder Satellite Observations (CALIPSO), J. Geophys. Res., 113, D00A14, doi:10.1029/2008JD009835, 2008.

Mace, G. G., Marchand, R., Zhang, Q., and Stephens, G.: Global hydrometeor occurrence as observed by CloudSat: initial observations from summer 2006, Geophys. Res. Lett., 34, L09808, doi:10.1029/2006GL029017, 2007.

Marchand, R., Mace, G. G., Ackerman, T., and Stephens, G.: Hydrometeor detection using CloudSat - an Earth-orbiting 94$\mathrm{GHz}$ cloud radar, J. Atmos. Ocean. Technol., 25, 519-533, doi:10.1175/2007JTECHA1006.1, 2008.

Marshak, A., Platnick, S., Várnai, T., Wen, G., and Cahalan, R. F.: Impact of three-dimensional radiative effects on satellite retrievals of cloud droplet sizes, J. Geophys. Res., 111, D09207, doi:10.1029/2005JD006686, 2006.

Matsui, T., Masunaga, H., Pielke Sr. R. A., and Tao, W.-K.: Impact of aerosols and atmospheric thermodynamics on cloud properties within the climate system, Geophys. Res. Lett., 31, L06109, doi:10.1029/2003GL019287, 2004.

Nakajima, T. Y. and Nakajima, T.: Wide-area determination of cloud microphysical properties from NOAA AVHRR measurements for FIRE and ASTEX regions, J. Atmos. Sci., 52, 4043-4059, 1995.

Nakajima, T., King, M. D., Spinhirne, J. D., and Radke, L. F.: Determination of the optical thickness and effective radius of clouds from reflected solar radiation measurements, Part II: Marine stratocumulus observations, J. Atmos. Sci., 48, 728-750, 1991.

Nakajima, T. Y., Suzuki, K., and Stephens, G. L.: Droplet growth in warm water clouds observed by the A-Train, Part II: A multisensor view, J. Atmos. Sci., 67, 1897-1907, doi:10.1175/2010JAS3276.1, 2010.

Nakatsuka, H., Kimura, T., Seki, Y., Kadosaki, G., Iide, Y., Okada, K., Yamaguchi, J., Takahashi, N., Ohno, Y., Horie, H., and Sato, K.: Design and development status of the EarthCARE cloud profiling radar, IEEE Int. Geosci. RemoteSensing Symp. (IGARSS), 2415-2418, doi:10.1109/IGARSS.2012.6351004, 22-27 July 2012.

Painemal, D., Minnis, P., and Sun-Mack, S.: The impact of horizontal heterogeneities, cloud fraction, and liquid water path on warm cloud effective radii from CERES-like Aqua MODIS retrievals, Atmos. Chem. Phys., 13, 9997-10003, doi:10.5194/acp13-9997-2013, 2013.

Parkinson, C.: Aqua: an earth-observing satellite mission to examine water and other climate variables, IEEE Trans. Geosci. Remote Sens., 41, 173-183, doi:10.1109/TGRS.2002.808319, 2003.
Partain, P.: Cloudsat ECMWF-AUX auxiliary data process description and interface control document, Cooperative Institute for Research in the Atmosphere, Colorado State University, 10 pp., 2007.

Platnick, S., King, M. D., Ackerman, S. A., Menzel, W. P., Baum, B. A., Riedi, J. C., and Frey, R. A.: The MODIS cloud products: Algorithms and examples from Terra, IEEE Trans. Geosci. Remote Sens., 41, 459-473, 2003.

Polonsky, I. N.: Level 2 cloud optical depth product process description and interface control document, Cooperative Institute for Research in the Atmosphere, Colorado State University, 21 pp., 2008.

Remer, L. A., Kaufman, Y. J., Tanré, D., Mattoo, S., Chu, D. A., Martins, J. V., Li, R.-R., Ichoku, C., Levy, R. C., Kleidman, R. G., Eck, T. F., Vermote, E., and Holben, B. N.: The MODIS Aerosol Algorithm, Products, and Validation, J. Atmos. Sci., 62, 947-973, doi:10.1175/JAS3385.1, 2005.

Schutgens, N. A. J.: Simulated Doppler radar observations of inhomogeneous clouds: application to the EarthCARE space mission, J. Atmos. Ocean. Technol., 25, 26-42, doi:10.1175/2007JTECHA956.1, 2008.

Sorooshian, A., Feingold, G., Lebsock, M. D., Jiang, H., and Stephens, G. L.: On the precipitation susceptibility of clouds to aerosol perturbations, Geophys. Res. Lett., 36, L13803, doi:10.1029/2009GL038993, 2009.

Sorooshian, A., Wang, Z., Feingold, G., and L'Ecuyer, T. S.: A satellite perspective on cloud water to rain water conversion rates and relationships with environmental conditions, J. Geophys. Res.Atmos., 118, 6643-6650, doi:10.1002/jgrd.50523, 2013.

Stephens, G. L. and Haynes, J. M.: Near global observations of the warm rain coalescence process, Geophys. Res. Lett., 34, L20805, doi:10.1029/2007GL030259, 2007.

Stephens, G. L., Vane, D. G., Boain, R. J., Mace, G. G., Sassen, K., Wang, Z., Illingworth, A. J., O'Connor, E. J., Rossow, W. B., Durden, S. L., Miller, S. D., Austin, R. T., Benedetti, A., Mitrescu, C., and Team, T. C. S.: The Cloudsat mission and the A-Train, B. Am. Meteorol. Soc., 83, 1771-1790, doi:10.1175/BAMS-83-12-1771, 2002.

Stephens, G. L., Vane, D. G., Tanelli, S., Im, E., Durden, S., Rokey, M., Reinke, D., Partain, P., Mace, G. G., Austin, R., L'Ecuyer, T., Haynes, J., Lebsock, M., Suzuki, K., Waliser, D., Wu, D., Kay, J., Gettelman, A., Wang, Z., and Marchand, R.: CloudSat mission: performance and early science after the first year of operation, J. Geophys. Res., 113, D00A18, doi:10.1029/2008JD009982, 2008.

Suzuki, K., Nakajima, T., Nakajima, T. Y., and Khain, A.: Correlation pattern between effective radius and optical thickness of water clouds simulated by a spectral bin microphysics cloud model, Sola, 2, 116-119, doi:10.2151/sola.2006-030, 2006.

Suzuki, K., Nakajima, T. Y., and Stephens, G. L.: Particle growth and drop collection efficiency of warm clouds as inferred from joint CloudSat and MODIS observations, J. Atmos. Sci., 67, 3019-3032, doi:10.1175/2010JAS3463.1, 2010.

Suzuki, K., Stephens, G. L., van den Heever, S. C., and Nakajima, T. Y.: Diagnosis of the warm rain process in cloudresolving models using joint CloudSat and MODIS observations, J. Atmos. Sci., 68, 2655-2670, doi:10.1175/JAS-D-1005026.1, 2011. 
Suzuki, K., Stephens, G. L., and Lebsock, M. D.: Aerosol effect on the warm rain formation process: satellite observations and modeling, J. Geophys. Res., 118, 170-184, doi:10.1002/jgrd.50043, 2013a.

Suzuki, K., Golaz, J.-C., and Stephens, G. L.: Evaluating cloud tuning in a climate model with satellite observations, Geophys. Res. Lett., 40, 4464-4468, doi:10.1002/grl.50874, 2013b.

Sy, O. O., Tanelli, S., Takahashi, N., Ohno, Y., Horie, H., and Kollias, P.: Simulation of EarthCARE spaceborne Doppler radar products using ground-based and airborne data: effects of aliasing and nonuniform beam-filling, IEEE T. Geosci. Remote, 52, 1463-1479, doi:10.1109/TGRS.2013.2251639, 2013.

Twomey, S.: The influence of pollution on the shortwave albedo of clouds, J. Atmos. Sci., 34, 1149-1152, 1977.

Wood, R.: Relationships between optical depth, liquid water path, droplet concentration, and effective radius in adiabatic layer cloud, University of Washington, 3 pp., 2006.
Zhang, Z. and Platnick, S.: An assessment of differences between cloud effective particle radius retrievals for marine water clouds from three MODIS spectral bands, J. Geophys. Res., 116, D20215, doi:10.1029/2011JD016216, 2011.

Zhang, Z., Ackerman, A. S., Feingold, G., Platnick, S., Pincus, R., and Xue, H.: Effects of cloud horizontal inhomogeneity and drizzle on remote sensing of cloud droplet effective radius: Case studies based on large-eddy simulations, J. Geophys. Res., 117, D19208, doi:10.1029/2012JD017655, 2012.

Zinner, T., Wind, G., Platnick, S., and Ackerman, a. S.: Testing remote sensing on artificial observations: impact of drizzle and 3D cloud structure on effective radius retrievals, Atmos. Chem. Phys., 10, 9535-9549, doi:10.5194/acp-10-9535-2010, 2010. 